\title{
A regional process under the international initiative for IFM
}

\author{
Masahiko Murase ${ }^{1, a}$, Yoichi Iwami ${ }^{1}$, Hisaya Sawano ${ }^{1}$, Yoshio Tokunaga ${ }^{1}$, Katsuhito Miyake ${ }^{1}$, Kuniyoshi Takeuchi ${ }^{1}$, and \\ Toshio Koike ${ }^{1}$ \\ ${ }^{1}$ International Centre for Water Hazard and Risk Management (ICHARM), Public Works Research Institute (PWRI), 1-6 Minamihara, \\ Tsukuba, Ibaraki 305-8516 Japan
}

\begin{abstract}
Climate change is likely to result in increases in the frequency or intensity of extreme weather events including floods. The International Flood Initiative (IFI), initiated in January 2005 by UNESCO and WMO and voluntary partner organizations has promoted an integrated flood management (IFM) to take advantage of floods and use of floodplains while reducing the social, environmental and economic risks. Its secretariat is located in ICHARM. The initiative objective is to support national platforms to practice evidence-based disaster risk reduction through mobilizing scientific and research networks. After its initial decade, the initiative is providing a stepping-stone for the implementation of Sendai Framework by revitalizing its activities aimed at building on the sucess of the past, while addressing existing gaps in integrated flood managemnet strategies comprising of optimal structural and nonstructural measures thereby mainstreaming disaster risk reduction and targeting sustainable development. In this context, a new mechanism try to facilitate monitoring, assessment and capacity building in the Asia Pacific region. The primary outcomes of the mechanism are demand-driven networking and related documentations of best practices for 1) hazard assessment, 2) exposure assessment, 3) vulnerability assessment and coping capacity to identify the gaps, and 4) follow-ups and monitoring of the IFM process.
\end{abstract}

\section{Introduction}

Flooding is one of the greatest water-related environmental disasters known to us - its human, material and ecological costs are staggering. The number of people vulnerable to a devastating flood is expected to continue to rise due to large-scale urbanization, population growth in flood-prone areas, deforestation, climate change and rising sea levels. New disaster risk reduction approaches are needed to build the necessary capacity to address these challenges.

On the other hand, floods are natural phenomena, which contribute to the biodiversity and sustainability of ecosystems and to many human activities. Both developed and developing countries have benefited from economic development in areas prone to flooding. Close to one billion people - one-sixth of the global population, the majority of them among the world's poorest inhabitants - now live in the flood plains. Developing countries with mainly agricultural economies depend largely on their fertile flood plains for food security and poverty alleviation. The deltas of many river systems favor low-tech agricultural practices and provide livelihoods for millions. The wetlands in flood plains contribute to biodiversity and also create employment opportunities. International Flood Initiative (IFI) made its official launch in January 2005 at the World Conference on Disaster Reduction (WCDR) in Kobe, Japan as a joint initiative between international organizations. With respectful contributions from participatory organizations, IFI has been making an effort to conceptualize, design and implement flood mitigation and protective actions and activities. Being intimately aware of the achievements that have been made in flood management in the last decade, IFI has also tried to foster the mobilization of resources and networks of the UN system, non-governmental organizations and so on in order to assist communities and governments in developing culturally sensitive flood management strategies and thereby addressing sustainable development.

\section{Disaster Risk Reduction framework}

The post-2015 framework (Sendai Framework) for disaster risk reduction (DRR) [1] was adopted at the Third World Conference on DRR in March 2015 in Japan, which represented a unique opportunity for countries to adopt a concise, focused, forward-looking and actionoriented DRR framework. States also reiterated their commitment to DRR and the building of resilience to disasters to be addressed with a renewed sense of urgency in the context of sustainable development and poverty eradication and, as appropriate, to be integrated into policies, plans, programs, and budgets at all levels and considered within relevant frameworks. National targets and indicators would contribute to the achievement of the outcome and goal of this framework.

\footnotetext{
${ }^{\mathrm{a}}$ Corresponding author: m-murase@pwri.go.jp
} 


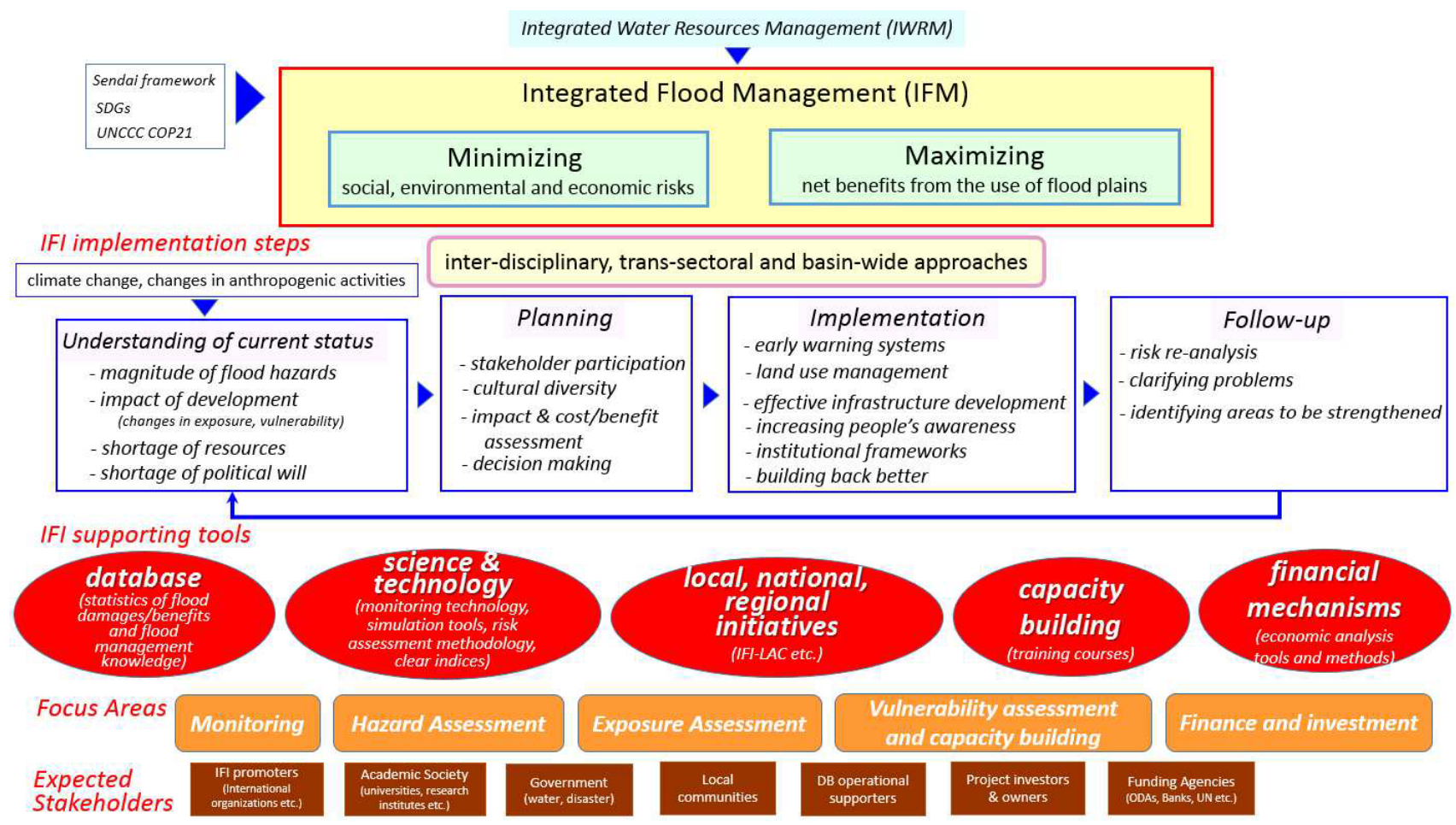

Figure 1. IFI Strategic Structure 2016-2022 [3].

The framework emphasizes the role of science and technology as the first of these four priorities, "Understanding disaster risk" lists as actions to promote the collection, analysis, management and use of data, the assessment of disaster risk, the use of geospatial information, and disaster-related education, dissemination and awareness raising. By expressing sincere appreciation to the valuable contributions from IFI partners in its initial decade, it is the time for IFI to provide a stepping-stone for the implementation of Sendai Framework by revitalizing its activities aimed at building on the successes of the past, while addressing existing gaps in implementing a holistic approach to flood management strategies comprising optimal structural and non-structural measures and thereby mainstreaming disaster risk reduction and addressing sustainable development.

\section{International Flood Initiative}

The International Flood Initiative (IFI) promotes an Integrated Flood Management (IFM) to take advantage of the benefits of floods and the use of flood plains while reducing the social, environmental and economic risks. IFM is a process promoting a holistic risk-based approach to flood management which aims at maximizing the net benefits from the use of flood plains and minimizing loss of life from flooding [2]. IFM integrates land and water resources management with respect to flood management within the broader context of integrated water resources management (IWRM). It includes institutional actors at all levels of flood management and recognizes the critical importance of stakeholder participation and cultural diversity in planning and implementation.

UNESCO and WMO, building on past cooperative successes, launched the IFI in January 2005 to address existing management gaps through a holistic approach and to provide a platform for further collaborative efforts. IFI is also working in close collaboration with the United Nations Office for Disaster Reduction (UNISDR), United Nations University (UNU), the International Association of Hydrological Sciences (IAHS), the International Association for Hydro-Environment Engineering and Research (IAHR), the Institute for Catastrophic Loss Reduction (ICLR) and International Institute for Applied Systems Analysis (IIASA).

The IFI strategic structure 2016-2022 is shown in Figure 1 [3]. The IFI secretariat is located in the International Centre for Water Hazards and Risk Management (ICHARM), Tsukuba, Japan, and coordinates the IFI activities to conceptualise, design and implement flood mitigation and protective actions and activities, using contributions from participatory organisations. ICHARM is an institute around 50 staffs as the part of a national research and development agency, which was established in 2006 under auspices of UNESCO to serve as the Global Centre of Excellence for water hazard and risk management by observing and analysing natural and social phenomena, developing methodologies and tools, building capacities, creating knowledge networks, and disseminating lessons and information in order to assist government and all stakeholders in managing risks of water-related hazards at global, national, and community levels through three pillars: research, capacity building and information networking [4]. Among of such activities, there can be 
seen the development of the Integrated Flood Analysis System (IFAS) including training for more than 1,000 participants in collaboration with ASEAN countries, the development of the Rainfall-Runoff-Inundation (RRI) model including the Indus River project with UNESCO and field activities including the development of damage fragility curve of flood and drought comprehensively and assessment of climate change impact.

Other UN agencies working on other aspects of flood management are also to be invited to contribute to the initiative. The international community has committed itself to finding new approaches to managing risk and addressing vulnerability, which includes prevention, mitigation, preparedness, response and recovery. IFI is working towards these goals and serves as an important evolutionary link in the transition between the implementation of the Sustainable Development Goals (SDGs) [5], as well as the Sendai Framework activities. Likewise, the IFI aims to promote the concept of integrated flood management by emphasizing the benefits that can be derived from floods while reducing flood losses.

Referring to the Tokyo Statement [6] regarding a new science and technology that consolidates DRR and sustainable development, IFI needs to :

- adopt a common methodology on data collection and economic analysis of disasters which can be practiced by national and local platforms to realize evidencebased policy making on disaster risk reduction that can be practiced globally

- enhance numerical pre-assessments of damages by various hazards based on inter-disciplinary knowledge to formulate preventive policies and strategies, and

- fully share these valuable "best practices" of disaster risk reduction that are based on scientific findings.

\section{Stakeholders and focus areas for IFI activities}

By taking advantage of the comprehensive expertise/experts' network provided by the IFI members and strengthening complement activities between them, a synergic and inter-disciplinary approach should be implemented to target the focus areas (Table 1) for the DRR steps of 1) flood hazard assessment, 2) exposure assessment, 3) vulnerability, current coping capacity, building resilient communities and preparedness assessment to identify remaining risks and finally 4) follow-ups and monitoring of the whole process.

Progress of activities is to be quantified through a Monitoring and Evaluation (M\&E) process that is an integral part of IFI. The focus areas in Table 1 show how to support national platforms to practice evidence-based DRR through monitoring, assessment, capacity building, synthesis, advice, communication and engagement. Regular follow-ups of all activities through this M\&E seek to identify the gaps where further actions are required. The M\&E process strives to quantify to which extent improvements are possible in the areas of flood loss reduction, deriving benefits from floods, coping capacity and the resilience of communities at risk, as well as the outreach-effectiveness of the programme through the availability and application of products developed by the IFI, such as guidelines, workshops, and courses.

\section{Flood Hazard Assessment \\ - Multi-hazard analysis \\ - Data for hazard assessment \\ - Hydrologic and hydraulic modeling \\ - Flood hazard mapping \\ - Effective forecasting and early warning \\ - Indicators}

\section{Flood Exposure Assessment}

- Data for risk assessment

- Hydrologic, hydraulic and economic modeling

- Flood mapping

- Indicators

Vulnerability assessment and capacity building

- Effective communication

- Preparedness

- Response to warnings

- Methodologies to account for multiple stressors, such as international research with droughts

- Estimating social, political, health, and ecological impacts

- Flood mapping

- Indicators

\section{Finance and investment}

- National and local platforms through data collection and economic analysis

- Estimating economic impacts including the benefits of floods

- Mechanisms (including financial) to increase coping capacity and resilience

- Structural and non-structural measures

- Indicators

\section{Monitoring}

- Data collection and sharing and standalization as a key action area

- Statistics

- Risk monitoring

\section{Synthesis}

- Clear and unambiguous scientific views on current state of knowledge and the ways to reduce significant human and economic losses for international policy use

\section{Communication and engagement}

- Inter-disciplinary and trans-disciplinary programs

- Coordination between governments and science and technology communities at national, regional and global levels

- Involvement of international and regional agencies to held at regional level for flood management

- International scientific advisory functions offering effectiveness assessments

- Organization of special sessions at the international conferences dealing with flood risk management 


\section{A regional process for IFI}

The greatest potential flood hazards occur in Asia, where, between 1900 and 2006, over 1200 floods claimed an average of 5300 lives per event and caused up to $\$ 207$ billion in economic losses. As the IFI activities are identified as a part of the IHP- VIII Theme 1 shown by UNESCO IHP [7], the IHP VIII timeframe (2014-2021) and accompanying milestones can be a good opportunity to check and monitor the progress and activities of IFI. Along with these international outputs, the regional outputs should support and link with inter-regional outputs. With strong climate change impacts expected to affect the water cycle, in particular the intensity and frequency of hydrological extremes, flood and drought management strategies have become the central element of adaptation strategies. As written above, the initiative is expected to facilitate the implementation of Sendai Framework by revitalizing its activities aimed at building on the success of the past, while addressing existing gaps in implementing a holistic approach to flood management strategies comprising of optimal structural and nonstructural measures thereby mainstreaming disaster risk reduction and targeting sustainable development. For the moment, it is reasonable to focus on practical scales for the IFI next decade for which further IFM implementation need to be step forward at regional levels. In this context, a new mechanism was discussed during the Asian Water Cycle Symposium in March 2016, Tokyo [8] to facilitate the IFM through monitoring, assessment and capacity building regionally, in Asia Pacific region. The international initiative through this regional process backed by a strong decentralized network of the partners could support countries that implement the IFM.

The regional process is expected to play an important role in water-related disaster risk reduction by developing collaborative frameworks with valuable "best practices" that are based on scientific findings, thus adopting a consensus-based methodology on data collection and economic analysis of disasters in order to realize evidence-based policy making on water-related disaster risk. The regional process would facilitate its partners' actions at the regional levels for cooperation for flood disaster risk reduction in order to foster more efficient planning, create common information systems and exchange good practices and programs for cooperation and capacity development, and then to adopt and implement national and local disaster risk reduction strategies and plans, across different scales with targets, indicators and timeframes, aimed at preventing the creation of risk, reducing existing risk and strengthening economic, social, health and environmental resilience. These partners here are expected to be voluntarily comprised by, inter alia, national, provincial and local government agencies involved in decision making and charged with a role in flood management (policy makers, flood management practitioners, development planners, disaster managers, national hydrological and meteorological services, etc.), river basin organizations, bi- and multi-lateral organizations involved in technical and financial cooperation, non-governmental, voluntary, or community-based organizations, in particular those working in flood affected areas, and universities and other research institutes.

\section{Critical issues for the regional process}

The output of the regional process can facilitate and enable the preparation, by widely understandable procedures, of regional, national and local maps of flood risk areas; profiles of country and local area risks in terms of the number of affected people; and the assessment of potential economic damage quantities. For these outputs, it is key to develop appropriate methodologies to identify flood hazards, quantify initial exposure, and risks remaining after the implementation of mitigation measures, as well as benchmarking risk and creating risk profiles. The consensus on such methodologies can support mainstreaming DRR for flood management at regional, national and local implementation. IFI through its activities by voluntary partners seek to create information and databases to facilitate decision-making and monitoring of flood risk reduction in order to

- make leaders understand the status of flood risk in countries and offer them decision alternatives;

- help practitioners to plan and implement effective flood management strategies;

- support the progress toward achieving the SDGs and the relevant global development targets on water and disasters;

- provide scientific tools for monitoring the progress of the Sendai Framework; and

- achieve the above in a seamless and effective manner.

The primary outcomes of each of the IFI activities contributed by participating organisations are demanddriven networking and related documentations of best practices at different scales as a benchmark at the initial pilot step in the Asia Pacific region (Figure 2). Communication and collaboration on the country/community/basin scale for benchmarking is expected to identify the gaps and seek best practice methodologies, which leads to a scientific back-up for decision-making and maintaining DRR knowledge on regional and inter-regional scales.

\subsection{Comprehensive risk management (End to End)}

Important global decisions were made and came to fruition in 2015, like the Sendai Framework and SDGs emphasizing the current disaster risk reduction on water hazard through a holistic view of the changes in hazards arising from climate change, and in vulnerabilities and exposures arising from societal and environmental problems. The regional process would seek the establishment of national platforms to integrate the assessment of hazards, exposures and vulnerabilities comprehensively, tentatively called 'End to End'. Pilot cases need the risk assessment of water related disasters, taking local conditions into account, and use the outputs to assist local communities in their own risk assessment and disaster risk reduction tailored to local backgrounds. 


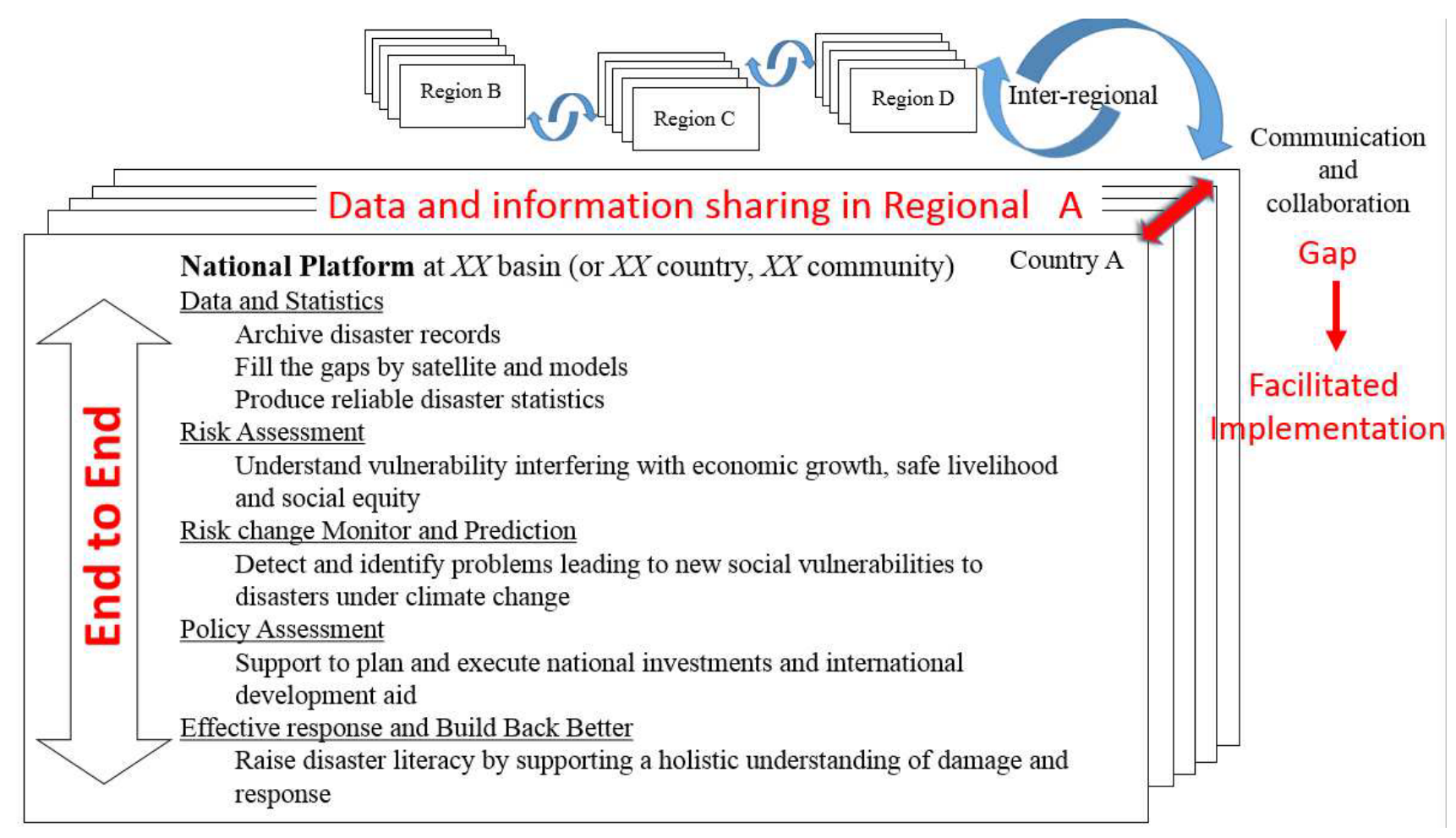

Figure 2. The structure of IFI regional process. [7]

\subsection{Data and information sharing}

Important global decisions also stressed the importance of future disaster risk reduction through monitoring and prediction of water related hazard risks based on the data and information. Sharing data and information can contribute effective disaster risk rediction, as 'evidencebased' policies. As a pilot process, a regional platform has been developed to share data and information with appropriate methodorogies in the Asia Pacific region [8]. Following the communication and collaboration in regional scales, monitoring efforts for the whole process to reduce flood risks aggregate for further inter-regional benchmarking as an important incentive to outside the region (Figure 2).

\subsection{Facilitated trans-disciplinary approaches}

Irrationally low priority of the investment in flood risk reduction creates many flood disasters and disturbs sustainable development. Trans-disciplinary approaches to visualize the effectiveness and efficiency on investments in flood risk reduction are required especially in the science and technology fields. The regional process should consider the analysis on concrete policy ideas in terms of adaptability to the actual field with considering the local lifestyle, socio-economic activities and future changes of risk, and build consensus among stakeholders in the context of sustainable development under climate change. It also develops methods and models capable of evaluating the socioeconomic effect of individual disaster related policies in the regional scale. The IFI regional process should facilitate trans-disciplinary approaches to the decision- making on investments in flood management by states and funding agencies.

\section{Concluding remarks}

As the Sendai Framework and SDGs in 2015 stressed the importance of future disaster risk reduction through monitoring and prediction of flood hazard risks, a practical action for step-forward would be sought for a regional process in the IFI. As was further discussed and agreed at the IFI session in the AWCS2016 [8], the implementation plan should facilitate the integrated flood management on Plan-Act-Check spiral process. In the Asia Pacific region, the major gaps could be identified and classified into two main areas; data limitations and society limitation. Further discussions then resulted in the set of five key actions for implementation: (1) data and statistics, (2) risk and resilience assessment, (3) risk and resilience change identification, (4) support in sound policy-making and (5) support in community of practice.

(1) data and statistics

- promoting data collection, storage, sharing and statistics

- integrating local data, satellite observations and model outputs

(2) risk and resilience assessment

- developing integrated disaster risk assessment

- identifying locality and commonality

(3) risk and resilience change identification - monitoring and predicting changes in disaster risk

- identifying locality and commonality 
(4) support in sound policy-making

- analyzing and formulating policies

- visualizing values of preparedness and investment efficiency

(5) support in community of practice

- improving disaster literacy

- promoting co-design and co-implementation among stakeholders

These are shown also in the Figure 2 as an example which is under discussion with the IFI partners. In this discussion, the timeframe for the regional process is expected to be set such as at the international conference on flood management (ICFM), which is held once every three years. Given the background of the IHP VIII [7] period, IFI Action List should be arranged and updated regularily.

\section{References}

1. UNISDR(2015): Sendai Framework for Disaster Risk Reduction 2015-2030, available at http://www.wcdrr.org/preparatory/post2015 (accessed on 19 April 2016)

2. APFM (Associate Programme on Flood Management) (2004):Integrated Flood Management- Concept Paper, World Meteorological Organization, Geneva, Switzerland, 27p

3. IFI (International Flood Initiative) (2016): International Flood Initiative Strategy 2016-2022, drafted and developed at www.ifi-home.info (accessed on 21 April 2016)

4. ICHARM (International Centre for Water Hazard and Risk Management) (2014) : Mission and Programs of ICHARM, available at http://www.icharm.pwri.go.jp (accessed on 19 April 2016)

5. United Nations (2015). Transforming our world: the 2030 Ageenda for Sustainable Development, the United Nations General Assembly Seventieth session Agenda items 15 and 116, A/70/L.1.

6. IRDR (Integrated Research on Disaster Risk) (2015): Tokyo statement, the Tokyo Conference on International Study for Disaster Risk Reduction and Resilience, 14-16 January 2015, available at: http://monsoon.t.u-tokyo.ac.jp/AWCI/TokyoConf/en/ (accessed on 19 April 2016)

7. UNESCO (2014): IHP Eighth Phase "Water Security: Responses to local, regional, and global challenges" Strategic Plan IHP-VIII (2014-2021), available http://unesdoc.unesco.org/images/0021/002180/2180 61e.pdf (accessed on 19 April 2016)

8. AWCS (Asian Water Cycle Symposium) (2016) : Towards International Flood Initiative (IFI) in the Asia Pacific Region and GEO Water, Flood Session summary, 1-3 March 2016, The University of Tokyo, all materials available at http://wci.t.utokyo.ac.jp/events/awcs2016/ (accessed on 19 April 2016) 